\title{
Albanian students' motives for preferring certain real-life situations for learning mathematics
}

\author{
Author: \\ Suela Kacerja ${ }^{1,2}$ \\ Affiliations: \\ ${ }^{1}$ Department of \\ Mathematical Sciences, \\ University of Agder, Norway \\ ${ }^{2}$ Department of \\ Mathematics, University Luigj \\ Gurakuqi, Albania \\ Correspondence to: \\ Suela Kacerja \\ Email: \\ skacerja@yahoo.com \\ Postal address: \\ St Olavs vei, 41-43, 4631 \\ Kristiansand, Norway \\ Dates: \\ Received: 12 Sept. 2011 \\ Accepted: 07 Nov. 2011 \\ Published: 30 Nov. 2011 \\ How to cite this article: \\ Kacerja, S. (2011). Albanian \\ students' motives for \\ preferring certain real-life \\ situations for learning \\ mathematics. Pythagoras, \\ 32(2), Art. \#50, 9 pages. \\ http://dx.doi.org/10.4102/ \\ pythagoras.v32i 2.50
}

(C) 2011. The Authors. Licensee: AOSIS OpenJournals. This work is licensed under the Creative Commons Attribution License.
This article reports on a qualitative investigation of Albanian students' motives for preferring certain real-life situations to be used in school mathematics, and possible connections of these motives to characteristics and issues within Albanian society. It is based on realistic interviews with students from Grades 8 and 9 in a school in the district of Shkodra in northern Albania. Interviews were conducted after students experienced five teaching units which dealt with mathematics embedded in real-life situations. Results are expressed in terms of contextmechanism-outcome configurations as proposed by critical realist theory. Most of the results are supported by those from a previous quantitative study which found that students prefer real-life situations which deal with computer games, being productive in a job, community development, and recreation, physical exercise and sport. An important mechanism uncovered in this study was the role of the mathematics that the topic introduced; degree of difficulty of the mathematics influenced the choice of preferred contexts by students. Preferences expressed by students are therefore to be considered with care.

\section{Introduction}

Inclusion of real-life situations in school mathematics textbooks and other teaching materials is discussed the world over (e.g. Department of Basic Education, 2010; Encyclopaedia Britannica, 2011; Julie, Holtman \& Mbekwa, 2011; National Mathematics Advisory Panel, 2008; Organisation for Economic Co-operation and Development, 2006; Qualifications and Curriculum Authority, 2007). Similar trends are emerging in the Albanian school mathematics curriculum, where importance is placed on the need for students to recognise and use mathematical concepts in everyday life and in other school subjects (Institute of Curricula and Training, 2008). The concepts of numeracy is introduced as the group of mathematical concepts and skills that serve an individual in everyday life, at home, in his workplace, in community' (Institute of Curricula and Standards, 2006, p. 2). Teachers are encouraged to bring examples from other school subjects into their mathematics teaching (Institute of Curricula and Training, 2007).

These latest changes in the Albanian school mathematics curriculum should be reflected in mathematics textbooks and other teaching materials, and by the teachers who are expected to introduce these changes to students in the classroom. However, during selection of the real-life situations to use in teaching mathematics, students' opinions are not usually taken into account.

It is important that students' voices are heard, yet there are virtually no research studies on students' preferences in terms of the real-life situations to be used in mathematics (Julie \& Mbekwa, 2005). There are indeed a few studies that include results about students' preferences for reallife situations as secondary ones. One study is presented by Kaiser-Messmer (1993) on gender differences in school mathematics in Germany, and one part of it deal with students' preferences for different contexts. She not only found differences in preferences according to gender but also according to grade and level of course taken in upper secondary schools. In general girls were more inclined toward social topics and boys toward sports and technology.

Other studies on contexts in school mathematics deal with matters such as the effects of realistic contexts on learning (Boaler, 1994; Cooper, 1998; Meaney, 2007) and assessment (Van den HeuvelPanhuizen, 2005), and how teachers use or choose contexts in teaching (Chapman, 2006; Pierce \& Stacey, 2006).

\section{Background of the study and research questions}

The study presented is part of a multi-country project, Relevance of School Mathematics Education (ROSME), and is focused on Grade 8-10 Albanian students' preferences of real-life situations to be used in mathematics. The target students in Albania are 13-15 years old. The ROSME project (Julie, 2007; Julie \& Holtman, 2008; Julie et al., 2011; Julie \& Mbekwa, 2005) aims to ascertain which 
real-life situations students in Grades 8-10 are interested in dealing with in mathematics. A pragmatic outcome of the project will be research-based information on real-life situations that students find attractive for learning resources, which curriculum developers and other interested parties dealing with development of meaningful mathematical activities for students will be able to use. However, it does not hold that mathematical activities should only be driven by students' interests.

Quantitative results of the ROSME project in Albania were reported in Kacerja, Julie and Hadjerrouit (2010), where a hierarchy of students' preferences for real-life situations in mathematics was obtained. In that earlier stage 24 interviews were held with students, referred to here as the 'first interviews', to ascertain their motives for preferences. Results discussed in this article are from a second stage of the study that was informed by earlier results. In this stage the students participated in lessons with various real-life contexts before being interviewed. Students' motives for preferences are explained using the realist research paradigm. The current study sought to answer the following research questions:

1. What are students' motives for preferring certain real-life situations for learning mathematics?

2. How, if at all, are these motives connected to contemporary issues in Albanian society?

\section{Theoretical foundations}

This research is situated within a non-naïve, realist paradigm. This is different from naïve realism, in which a one-to-one relationship of reality and our description of it are assumed (Pring, 2004). The main reason for choosing this paradigm was the belief that reality, that is, that students' preferences for contexts exist, and thus an objectivist ontology is accepted. This reality is separated from our knowledge of it and is obtained through human cognition, so is subjective (Au, 2007).

In a realist paradigm a theory is given by the equation outcomes = mechanism + contexts, which mean that:

'outcomes' (are realised) only in so far as they introduce the appropriate ideas and opportunities ('mechanisms') to groups in the appropriate social and cultural conditions ('contexts').

(Pawson \& Tilley, 1997, p. 57)

In this study students were taught five mathematics units dealing with real-life situations. The outcomes were students' preferences as assessed through interviews, and the underlying mechanisms were students' motives for their preferences. Referring to Pawson and Tilley (1997, p. 66), to identify mechanisms in our study is to develop propositions about what it is in the mathematics lessons with real-life situations that drives students to have a positive, negative or neutral opinion about them. Finding the mechanism, that is itself 'a theory which spells out the potential of human resources and reasoning' (Pawson \& Tilley, 1997, p. 68), is to put together individual reasoning (choices) and collective resources (capacity).
The starting point in finding a configuration of contextmechanism-outcome and testing and refining it is to conjecture about what might work, for whom and in which contexts, which is tested during data collection. Students were asked directly about reasons for their preferences, but we cannot pretend that they are totally aware of the bigger picture; it is required of the researcher to conjecture about students' reasoning in a wider and more complete context.

Students included in the study were members of Albanian society, members of various families, studying at a certain school, belonging to certain groups and therefore having their own habitus (Bourdieu, 1977) or history that shapes how they see the present and the future, which makes them perceive opportunities in specific ways. Hence one should also take into account the context in which the units are introduced, not just the physical context but also the social norms, values and rules embraced by inhabitants of that physical location, since a mechanism can be activated or deactivated depending to a high degree on the context (Pawson \& Tilley, 1997). In considering students' motives for their preferences it was therefore important to refer to the Albanian social environment where their habitus were shaped.

\section{Research design Research approach}

The study presented used realistic interviews to gather data in order to answer the research questions. These interviews followed the experiences the students had with five teaching units of mathematics in real-life situations.

\section{Data collection and participants}

The teaching units: The students participated in five units of mathematics embedded in real-life situations. In each of the units students learned about one real-life situation whilst using mathematics; this varied from application of known mathematics to relatively new mathematical knowledge for the students. Five contexts were selected for the units: development indexes, lotteries and gambling, sport tournaments, secret codes and sending SMSs. These were chosen from different positions in the hierarchy of preferences that arose from the quantitative data analysis in 2008, from highly preferred to moderately preferred and least preferred items (Kacerja et al., 2010).

The most preferred item of the questionnaire was 'Determining the level of development regarding employment, education and poverty of my community', and this was the realistic situation for one of the lessons. In this lesson information from the Human Development Index (HDI) used by the United Nations Development Programme (2009) to measure the degree of development of countries of the world was introduced to students. They learned how the HDI for each country is constructed, calculated Albania's HDI, and their homework was to collect data in their neighbourhood to calculate a simpler development index for 
the area they live in and to discuss it. The main mathematics concept here was the construction of a social index, which is normally embedded in econometrics and was in a sense new mathematics to them.

One of the lesser preferred situations, ordered as 21st amongst 23 items in the 2010 questionnaire (Kacerja et al., 2010), was 'lotteries and gambling'. During the first interviews (Kacerja, 2009) students referred to the negative material and social consequences of gambling. Therefore one part of the lesson included a discussion of the following quote by Einstein: 'You cannot beat a roulette table unless you steal money from it', after doing the mathematics and calculating different probabilities.

One of the moderately highly preferred topics contextualised was about sport tournaments as part of the item 'recreation, physical exercise, sport activities and competitions', ranked 9th. The lesson brought to the fore elements that had to do with the number of teams and matches in a single-elimination tournament in sports such as basketball or football. The mathematics dealt with powers of a number and multiples, which they already knew from school mathematics, and geometric sequences, which were new to them.

One of the medium-preferred items was 'secret codes such as PIN numbers', ranked 14th on the questionnare. A lesson on secret codes and algebra was adapted from a chapter of the Consortium for Mathematics and its Applications 1998 book Modeling our world: Course 1. Students learned how to code a phrase by shifting letters or numbers, and how to decode a message coded by someone else. Elements of cryptography were employed. Students used different linear functions that were not totally new to them.

One of the highly preferred items, 'sending and receiving electronic messages' (ranked 6th) was used for one topic about cell phone messages. Students learned the route traversed by an SMS as it moves from one mobile phone to another, the time taken for the call to be serviced, and the waiting time in a queue. The information students received from this lesson was new to most of them. The mathematics included some simple elements of queuing theory.

\section{Participants and procedures}

A lower secondary city school was selected for data collection on the basis of the school principal's willingness for collaboration after being contacted and having the study, its aims, the way the data would be collected and materials to be used for this purpose explained. The school was selected for convenience, and does not have a reputation for being the highest or lowest quality school in the city of Shkodra.

The mathematics teacher who collaborated with the researcher was asked to form a class with 22 students from Grades 8 and 9, from amongst those who volunteered to participate. Students were selected to ensure a gender balance and a mixed-abilities group in terms of their mathematical skills, so that the group would be as diverse as possible.
In order not to interfere with normal school lesson plans, the five teaching units were conducted after normal school hours as extra lessons for students. Each of the five teaching units lasted 45 minutes. The researcher was also the teacher of the lessons. The routine followed in every lesson was similar to that which the students were used to at school: the topic and some information about it were introduced, then the different sections or exercises were completed. Some of the exercises were solved jointly on the blackboard, some individually in the classroom, and others were given as homework.

After the five teaching sessions students were asked to volunteer to be interviewed. Eighteen students volunteered and eight of these were selected to be interviewed. The gender balance was again a factor for selection, together with different degrees of students' engagement during the lessons. Students were interviewed individually at their school by the researcher for not more than 30 minutes. The procedure employed in each interview was the same: students were asked to place the five lessons in decreasing order of preference and to state the reasons for liking or disliking each of them.

\section{Ethical considerations}

Since no ethical guidelines exist for research in Albania, both the school principal and the teacher were present when the project was explained to students and they were invited to volunteer to participate. All students who volunteered to participate signed a declaration that they understood the project and what was required of them, and they also informed their parents. In the excerpts from interviews below the initials used are pseudonyms to ensure students' anonymity.

\section{Research method}

\section{Realistic interviews}

Realistic interviews seek to answer as to what works for whom in which circumstances (Pawson, 1996). Realistic interviews are in line with the realist paradigm that guides the study. The researcher already had an initial theory or conjecture about the matter at hand, from previous stages of the study, in terms of initial mechanisms and contexts. The strategy followed was therefore theory-driven: 'The researcher's theory is the subject matter of the interview, and the subject (stakeholder) is there to confirm, to falsify and, above all, to refine that theory' (Pawson \& Tilley, 1997, p. 155).

The aim was to assess Albanian students' opinions of the five mathematics units which they were taught, and to establish the motives that guided their choices. Interviews were conducted in Albanian.

A realistic interview starts with the researcher's theory and goes through four stages that can be repeated in a cyclical way. The first two stages have to do with a 'teacher-learner function'. Here the interviewer's active role is to inform 
or teach the interviewee the conceptual structure of the interview, its purposes and meanings, in order to have a common understanding. By doing so the interviewee will understand the nature of the information being sought, and why it is sought (Pawson, 1996). In the introduction the researcher declared the object of the interview and explained its general aim as follows:

I would like to know about the activities we did together, what are your interests, how did you like those, why do you like something and not something else. The idea in this interview is that I want to know from you why you like some ... i.e. what interests do you have to learn the mathematics that is used in some fields, that is applied in these fields, and why do you like it, or what are the fields you like more, why do you like those, what do you connect those with.

The two main concepts of the study, students' interest in real-life contexts in mathematics lessons and the reasons for their preferences, were introduced to the interviewee. It was emphasised that it was the students' opinions that were being requested.

Using the five units as a common basis for interviewing contributed towards mutual understanding, gave students some examples to think about, and made it possible to move from specific to more general discussions. Teaching of the conceptual structure during the first two stages continued, by stressing the significance of students' openness in declaring their liking or disliking of any or all of the lessons, offering them a conceptual structure in answering, and clarifying the interview structure:

I want to know what you really think about these, so if you don't like something you are free to say 'I don't like this because...' and you tell your reasons. If you like something you normally say it with the reasons too.

After the students ordered the five lessons from the most to the least preferred, the researcher went through each of the topics. In all of the following interview excerpts the notation $\mathrm{R}$ is used for the researcher, and $\mathrm{A}, \mathrm{B}$ and so on for the individual students.

R: Good, let's start with 'sending SMSs', which you ordered first. Why is that?

The students then answered questions about the reasons for their preference, keeping in mind the concepts mentioned earlier by the researcher. In this instance student $B$ responded as follows:

B: This is the topic I liked more because we use mobile phones every day and we send SMSs, but without knowing the time which we wait or the time when the SMS arrives, how it arrives. I liked it very much because ... I have learned something new about sending SMSs and I have some more knowledge than I knew [before] about this topic ... that's all about it. (Girl, Grade 9)

In this way the student goes from the second stage, where a conceptual structure is learned, to the third stage, where she applies this structure to her answers.

The two last stages are included under a 'concept refinement function', where the students express mechanisms, that is, motives that drive their preferences for specific contexts, to inform the researcher's theory. The researcher applies these mechanisms to the initial conjectures and presents the finding to the students, who can then agree, disagree, or refine the theory's conceptual basis. At this stage explanations, checking and repeated questions are important elements. The following is an example of the researcher applying the student's reasoning to the theory, extracted from her previous answers, and offering it to the student to comment upon:

$\mathrm{R}$ : So in order for a topic to be attractive, interesting for you, should it be something you do?

B: Hmm, there are also some things that one doesn't do and which one is interested to know, but things one does in everyday life are more interesting to know compared to others.

Here the researcher was trying to clarify the role of the 'everyday use' as a mechanism in the student's preferences. The student's answer refined the researcher's understanding about the connection between everyday life situations and interest in learning the mathematics used in these situations. The interviews continued like this in a cyclical manner until the researcher had clear answers to the questions and conjectures she had.

\section{Reliability and validity}

To ensure reliability, care was taken to formulate questions as clearly as possible for every student. Considerable time was taken during the whole study to emphasise the need for the students' input on their reasons for preferences. Anonymity of the interviews was ensured and students were informed in advance about the aims and objectives of the study. The interviewer was careful to avoid as much as possible any judgement of students' answers, and to create a feeling of confidence during the interviews. Reliability in interviews is related to ability to replicate the findings at other times, by other researchers (Kvale \& Brinkmann, 2009). One thing that might put reliability at risk is that preferences can be time-bound but, as this study tries to show, preferences are influenced to a great degree by the societies in which individuals live. Thus huge changes are not to be expected in short periods such as the time needed for this study.

Referring to Pawson and Tilley (1997), in a realistic interview the question of validity is not whether the data reproduce exactly the students' beliefs, but whether they capture the relevant concepts for the researcher's theory. During interviews the students' thoughts and the researcher's interpretations were continuously validated by the researcher, whilst applying students' answers to the initial conjectures and asking repeated questions to check meaning.

\section{Initial mechanisms and contexts}

In realistic interviews the researcher already has some initial conjectures about possible mechanisms, that is, motives, which drive students' preferences and the context in which the teaching takes place, but also the broader context of the community. The following mechanisms are based on 
data collected from the first interviews with students and on the ROSME study in South Africa (Julie, 2009), and are accompanied by some contexts within Albanian society.

'Lotteries and gambling' are deemed an inappropriate real-life context to be used in mathematics because of their undesirable effects (both social and material) on people's lives. This is supported by a general negative opinion about the topic in Albanian society, which is hypothesised as a possible mechanism for low preference for use of this reallife context in mathematics.

Albanian students participating in the first interviews expressed great interest in a secure future economic situation and upward mobility in life; thus connectedness of real-life situations to their future interests is a possible mechanism for preference. Most parents want their children to achieve at school in order to have better possibilities for the future, and high school students themselves want to achieve in order to find a good job and attain a higher standard of living by studying further at university (World Bank, 2005).

Students' affiliation to and use of modern technologies for communication, such as 'sending and receiving SMSs' or for safety in transactions such as 'secret codes such as PIN numbers', is a mechanism that can make a topic interesting for them.

In the South African ROSME study a mechanism that came across was 'community matters' (Julie, 2009); that is also important in Albania, a country with a developing economy. Regarding the general context of Albanian society, there are three important aspects: transition from a 45-year-old communist totalitarian system to a market economy in 1990, with all the changes and challenges it carried; an economy where high poverty and unemployment rates predominate, especially in rural areas; and internal and external migrations (Sultana, 2006) which have changed the structure of cities and brought phenomena such as brain and skills drains.

\section{Findings}

Interviews were audio-taped, transcribed and analysed to identify categories which would characterise mechanisms driving the students' preferences for real-life situations to be used in mathematics. These mechanisms, defined as students' motives for preferences, are now described and illustrated.

\section{New knowledge}

In many cases students mentioned that much of the information they received whilst participating in the lessons was new to them. For example, a Grade 8 girl (G) said: 'I have learned things I didn't think I would learn [in mathematics]', referring to the unit about secret codes. Students valued this as something which helped them to enrich their background, as demonstrated by another Grade 9 girl (B), who asserted that: 'this [development indexes] is a topic that makes you have a broader horizon [background].' D, a Grade 8 girl, said: 'we get more information and we have a larger background.' This mechanism was mostly mentioned in connection to other, more relevant mechanisms in order to add to the positive effect of them. Its influence will therefore be discussed below.

\section{Everyday use}

This category includes comments that students made about familiarity with a context, such as: 'I chose sport tournaments first because I like football, but also because I know how they are organised' (L, boy, Grade 8). Everyday use of a context was also directly mentioned by B (girl, Grade 9): 'This is the topic I liked more because we use mobile phones every day and we send SMSs.'

At the same time as the everyday use of a context influenced its choice, distance from it resulted in lack of interest from the students. This was the case, for example, for a boy (L, Grade 8) who expressed his disinterest in learning mathematics used in agricultural matters since 'I don't think I will ever deal with agriculture'.

\section{Usefulness and relevance}

Terms used by students such as 'useful', 'usable', 'valuable', 'needed', 'important', 'relevant' and so on are included in this category, which was mentioned most often during interviews. In most cases it was a good reason for guiding choice of a context:

... because sending SMSs is less valuable than indexes, much less valuable. (M, boy, Grade 9)

When I chose indexes before, it was ... it was more ... more necessary than this, lotteries. (A, boy, Grade 8)

Because it is useful information in general, but also on mathematics part. (D, girl, Grade 8)

The usefulness of the contexts for actual or future life is emphasised and characterised as part of this category:

Yes, I liked it [indexes], because they are useful things in life. (G, girl, Grade 8)

This topic [lotteries] is ... it gives you a ... it teaches you a lesson, so in the future one should have in mind that these are to do with fate and it's not that one can win with these. (A, boy, Grade 9)

The same student would be highly interested 'about things that have to do with my future'. Lack of perceived personal relevance of a context is a factor for according it lesser preference. This is supported by a Grade 8 girl (G), who said 'I don't like mathematics used in agriculture because it is not relevant for me, since I will not do agriculture in the future'.

\section{Personal interest in a context}

This category showed more interest when students were asked about the topic of sport tournaments. Most of the boys expressed their personal interest in sports as an activity they personally do or follow closely:

... because sport is one of my favourites. (M, Grade 9)

I liked this [sport tournaments topic] because I like sports very much and I liked this lesson better. (A, Grade 8) 
I chose first sport tournaments because I like football, but also because I know how they work (L, Grade 8).

Another Grade 9 boy (A) chose sport tournaments first and reasoned as follows:

I liked it, for example, because it gave me more knowledge about teams, how the Champions League is organised, how many matches there could be, things I didn't know ... [I liked] the way this topic is organised, since it is also an entertaining topic and sports are something I like, for these reasons...Yes, [I have $]$ an interest in sports.

A response from a girl, G (Grade 8) points towards a lack of personal interest in sports as a reason for not preferring the topic sport tournaments: 'I am not a sports fan, I don't like them either.'

\section{Perceived entertainment value}

Entertainment was often mentioned during interviews, when lack or presence of entertaining elements was perceived and used to describe lessons:

Entertaining, and the lesson I enjoyed the most. (G, girl, Grade 8)

I would like [to have a topic such as sport tournaments in my mathematics textbook], because it would be an entertaining lesson. (A, boy, Grade 9)

... it's not just mathematics, it is entertaining also. (D, girl, Grade 8)

For some students the degree of entertainment overrides other aspects when choosing a preferred lesson.

\section{Community matters}

Under this category are incorporated mainly aspects from the lesson about development indexes, where relevance of information about one's country and community is at the centre. Students' interest is clearly accompanied by their feelings of responsibility to know about their country 'because it is in everyone's interest to know more about our country and many other countries' (A, boy, Grade 8). As one girl put it, 'since we live in this country, we should know our economic percentages [meaning economic figures and indexes], how developed is our education, to know the development of the country we live in' (B, Grade 9).

However, even with its relevance this topic was not one of the most preferred, because of mathematics aspects which will be discussed further.

\section{Distance from gambling}

Gambling was one of the most discussed topics during the first interviews (Kacerja, 2009) because of its negative effects. In the current realistic interviews students expressed distance from it as an activity that they never take part in. They gave reasons such as:

I wouldn't do it myself, and I would advise my friends not to do it. Because I have learned in this lotteries topic that the probability [to win] is very low if we gamble. (B, girl, Grade 9)
Gambling is seen as an activity that only boys can do, whilst '[girls] during their life they don't have possibilities to deal with lotteries' (A, boy, Grade 9).

\section{Mathematics}

The effect of mathematics has to be considered, since it emerged in the interviews that it was one of the mechanisms often mentioned as influencing students' choice of contexts. The students mostly talked about the degree of difficulty and 'trickiness' of the mathematics:

Secret codes, I liked it, it was not so tiring topic ... I liked it also because mathematics was of a lower level [means easier] than the everyday [school] mathematics. (B, girl, Grade 9)

[Indexes topic] has too many calculations, and one can get lost, it's tricky and it looked to me more like a difficult mathematics lesson than entertaining like others. (A, boy, Grade 9)

I liked it a little bit [indexes] but the problem was that it was tricky [mathematics] and I put it lower than others. (L, boy, Grade 9)

As can be seen, the mathematics is the overriding issue; this relationship is a matter requiring further research.

\section{Context-mechanism-outcome structure of students' answers}

The characteristic of all of the mechanisms presented above is that when combined with each other, their effects change: the same mechanism can produce different outcomes. For example, the everyday use of a context, modern technologies such as sending SMSs, accompanied by new information about it can give rise to disinterest (outcome O1) when it is not perceived as relevant or valuable to the students. However, everyday use of modern technologies for communication (sending SMSs), including security matters (secret codes), accompanied by new information about it when 'it is like a game' (A, girl, Grade 8), highlight its utility value and intrinsic quality. For example: '[secret codes could be used] when I don't want to say something out loud, I can talk with codes with my friends' can result in increased interest (outcome O2), enthusiasm and students' engagement in mathematical activities (outcome O3).

For all these mechanisms, the contexts that make it possible for them to induce the respective outcomes are related to students' age (13-15 years), and their knowledge of and the possibility of them using modern technologies. Even though Albania is one of the poorest countries in Europe, its figures in terms of using mobile phones are higher than averages in the European Union. PIN codes are also used extensively in mobile phones, ATM machines and so on.

When accompanied with the mathematics involved, another important mechanism, community matters, brings about two different outcomes. Community matters bringing new information are perceived as useful in education, occupations and life in general, and can lead to elevated interest (O2) in following and learning the lesson. However, when the unit is identified by students as using difficult mathematics and too many tricky calculations requiring more attention, the same 
mechanisms and contexts can end up at a lowered or lost level of interest (O4). This is one of the cases of mathematics overriding context choice, as happened for this girl: '[Indexes] would have been first on my interest, but because it has many calculations I put it third' (B, Grade 9).

The greater context of Albanian reality is also an indicator and predictor of the relevance perceived by students. Issues about community matters, such as health, education, poverty and unemployment, are sensitive and perceived by students as such. Therefore following higher studies that will lead to a good and stable job in order to have a safe future is in itself a desire and objective for Albanian youngsters, as L (boy, Grade 8) states:

[In the future] I wanted to be a lawyer, but there are too many of them now, I should find another field ... If you want to find a job when you grow up, there are many [lawyers] and you don't find it.

The everyday use of sports topics associated with boys' personal interest in sports as a preferred activity in which to participate or watch, conveying new information, makes boys recognise it as a relevant and entertaining topic, which can therefore result in a higher level of interest $(\mathrm{O} 2)$ in learning mathematics. This is not the case with girls; since sports are not of everyday use to them, their personal interest in sports is also not that developed. In the absence of these two mechanisms, girls' interest in the unit is low (O1).

At the basis of students' answers about lotteries and gambling was their positioning of themselves at a certain distance from it. Albanian students participating in both stages of the ROSME study admitted that they have either used lotteries very seldom or not at all, but that friends around them use them. This has to be understood within the larger reality of Albania, where gambling was considered a negative, illegal behaviour during the communist era (1945-1990). Nowadays lotteries and gambling are a growing industry regulated by law, the phenomenon remaining mainly a male one. Even though it is illegal for people under 21 years to gamble, school children still enter casinos or gambling establishments (Gambling pushes minors toward crime, Gazeta Shqip, 30 January 2009).

\section{Discussion and conclusion}

The current study aimed to uncover students' motives for choosing their preferred real-life situations for use when learning mathematics. These motives are presented here under the label of 'mechanisms' as part of a realist paradigm. The same research question (the first one) drove an earlier, qualitative part of this study based on interviews with students in Grades 8-10 (Kacerja, 2009). In the research presented in this article, the difference is that students were interviewed after they had experienced mathematics embedded in some real-life situations that they were then asked about. The purpose of introducing this difference was to ascertain earlier found mechanisms, and to determine whether the teaching units would add further mechanisms.
The second research question was to detect and explain any connection between students' motives for preferences and societal matters in Albania. By formulating the contextmechanism-outcome structure from students' answers, an answer is provided to this question. Albanian societal matters are introduced above as contexts for the realistic theory, and their influence on students is disclosed as part of the realist equation outcomes = mechanism + contexts. Some of the views that students expressed during realistic interviews reflected some tendencies of Albanian life. This can be seen, for example, in students' distance from gambling as an activity which in the Albanian community is considered problematic and not desirable. Another tendency was expressed in students' need for a good education and work position as desired outcomes for a satisfying life. A study by the World Bank (2005) revealed that most Albanian parents want their children to achieve at school in order to have better possibilities for the future. One can therefore see the parents' ideas reflected in their children's objectives.

Further examples can be connected with students' interest in community matters as important aspects in a developing country. During interviews one student discussed the economic crisis, using the example of remittances from Albanian emigrants for their families in Albania to explain the relevance of being knowledgeable about one's country. These issues are objects of everyday discussion everywhere in Albania.

The realist approach embraced in this study made it possible to consider not only students' motives for their expressed preferences, but also to relate these motives to the context of the students' everyday life in their community. This helps to find the roots of their motives in the influences that society exercises on students. The key matter in the realistic interviews is the flow of information which, as explained earlier, allows the understanding of concepts and conjectures to be assessed by both participants in the interview (Pawson \& Tilley, 1997). This openness allowed continuous checking of the meanings obtained from the conversations.

One of the confirmed motives was connected to lotteries and gambling, which, as argued above, is connected to recent developments in the Albanian context. Gambling was considered as a male activity by students, as is the case in the greater Albanian society. It was, however, noticed that during interviews students saw a possible use for the information they received from the lesson, to advise friends who deal with gambling. This result is to some degree different from those of previous questionnaires, where the topic was amongst the least preferred, and from the first interviews where only the negative aspects of gambling were highlighted. A similar finding was presented in South Africa, where the mechanism was defined as 'personal regression via irresponsibility and/or addiction' (Julie, 2009). We can speculate here that putting the teaching unit's emphasis on being able to calculate gambling's negative consequences in order to become aware of its dangers helped in making students' attitudes towards learning the mathematics related 
to the topic more positive than in previous results. This issue of least preferred real-life situations, where an appropriate mathematical treatment of the context can contribute to learners engaging with it in a more informed manner, has been discussed previously (Kacerja et al., 2010).

Students' affiliation with modern technologies, a motive revealed by the first interviews, manifested itself in their everyday use of technologies and was related to the topics 'sending and receiving SMSs' and 'secret codes', ordered 6th and 14th respectively in the list of preferences (Kacerja et al., 2010). In the realistic interviews this difference is inverted. The same mechanism in the two topics generates two different results: the first topic is mentioned for its lack of relevance, whilst the second one is perceived as entertaining. This is an indicator of the relevance of integration of mechanisms and the influence of contexts.

Personal interest in an activity and perceived entertainment value are two other motives occurring in most responses during the interviews, seen as desirable qualities for a topic to be preferred. This was the case with the item 'sport tournaments', that was clearly more preferred by the boys; for girls the lack of the two motives made it uninteresting to them. However, no gender differences were found on the item 'recreation, physical exercise, sport activities and competitions', which means that the choice of a topic belonging to the same item can also make a difference. In terms of social life in Albania, for boys (especially those playing football or basketball) following national or international matches, wanting to be football players in the future and discussing sports are very usual, but it is not the same for girls.

The influence of the Albanian reality in students' preferences is also highlighted in connection with the 'community matters' mechanism, and is emphasised in the 'development indexes' topic. The relevance of the topic for their future educational and professional life, as a motive, was closely connected to this as well as to other topics. The two mechanisms find their reflection in the 'need for a safe economic future and upward movement' as a motive disclosed during the first interviews. Findings from the qualitative data are consistent with those from the quantitative data.

One mechanism displayed for the first time during this stage of the research was the issue of the mathematics introduced in the lessons. In some cases this mechanism overrode the choice of the topic, as happened with the 'development indexes'. The difficulty of mathematics, its trickiness, and the amount of calculations steered students' interest away, even with the topic's perceived relevance. However, it is impossible to find a connection between students' characteristics and lowered interest because of difficult mathematics, nor between the kind of mathematics and the degree of interest, from the data obtained. Further research is needed to explain this relationship.

Related to this latter topic, care should be taken to consider the quantity and difficulty level of new concepts (such as life expectancy, gross enrolment ratio, adult literacy index and gross domestic product [GDP]) when introducing these to students. Apparently these notions require more time to be grasped; thus a unit like this could be extended over two or more lessons to facilitate understanding. Other units could also be extended to two lessons in order to create some space for discussions about each topic, concepts and knowledge used or gained, and generalisations. Some discussion was included in each topic as part of the unit, but it is seen that discussion is crucial to enhance critical thinking which, from personal impressions seems to be missing or at least not so developed in Albanian schools. A study by Sahlberg and Boce (2008) supports this impression, and points toward development of productive learning of the skills needed within a knowledge society. These issues and education in general are especially vital in Albania, for their contribution 'to furthering democracy, to promoting an active citizenry, as well as to creating a vibrant, skilled workforce essential to the country's competitiveness, especially in a context marked by resource scarcity' (Sultana, 2006, p. 10).

Amongst the contexts that influence the level of preference of a teaching unit described in this article, the context of the classroom environment is equally important. Students confirmed that they enjoyed the topic 'secret codes' the most, not only because it was entertaining but also because they could work together and everyone could participate. This suggests that such topics can be even more interesting if there is a classroom climate where participation, discussion and critical thinking are appreciated and fostered. Other factors of influence could be the design of the lesson, the way it is taught and the relationship created between teacher and students, as in every other lesson. It must be emphasised that the focus of this study was the real-life situations and students' perception of these.

Questions of generalisation relate to discussion of results as being time-bound, as mentioned in the section on reliability. Kvale and Brinkmann (2009, p. 265) argue that 'analytical generalisation may be drawn from an interview investigation regardless of sampling and mode of analysis'. It requires detailed descriptions and arguments about the transferability of results to other subjects and situations. In this study the findings can be generalised at a local level, namely in terms of Albanian students. This can be said since, as discussed above, some issues, values and norms in Albanian community are reflected in the students' words when giving their reasons for preferring or not preferring to learn mathematics in specific contexts.

\section{Acknowledgements}

My special thanks go to my supervisors Cyril Julie and Said Hadjerrouit for reading and commenting on several drafts of the manuscript.

\section{Competing interests}

The author declares that she has no financial or personal relationships which may have inappropriately influenced her in writing this article. 


\section{References}

$\mathrm{Au}, \mathrm{W}$. (2007). High stakes testing and curricular control: A qualitative metasynthesis. Educational Researcher, 36, 258-267. http://dx.doi. org/10.3102/0013189X07306523

Boaler, J. (1994). When do girls prefer football to fashion? An analysis of female underachievement in relation to 'realistic' mathematics contexts. British Educational Research Journal, 20(5), 551-564. http://dx.doi org/10.1080/0141192940200504

Bourdieu, P. (1977). Outline of a theory of practice. Cambridge: Cambridge University Press.

Chapman, O. (2006). Classroom practices for context of mathematics words problems. Educational Studies in Mathematics, 62, 211-230. http://dx.doi.org/10.1007/ s10649-006-7834-1

Consortium for Mathematics and its Applications (COMAP) (1998). Modeling our world: Course 1. New York, NY: W.H. Freeman.

Cooper, B. (1998). Using Bernstein and Bourdieu to understand children's difficulties with 'realistic' mathematics testing: An exploratory study. International Journal of Qualitative Studies in Education, 11(4), 511-532. http://dx.doi. org/10.1080/095183998236421

Department of Basic Education. (2010). Curriculum and assessment policy statementMathematics: Senior phase. Pretoria: Department of Basic Education.

Encyclopaedia Britannica. (2011). Correlations of mathematics in context to common core standards for mathematics. Available from http://mathincontext.eb.com/ MiC\%20correlated\%20to\%20CCSS.pdf

Institute of Curricula and Standards. (2006). Program mesimor per arsimin e mesem te ulet. Lenda: Matematike (Klasa e tete) [Curriculum for lower secondary school.
Subject: Mathematics (Grade 8)]. Available from http://izha.edu.al/programet/ Subject: Mathematics (Grade
klasa8/Matematika\%208.pdf

Institute of Curricula and Standards. (2007). Program mesimor per arsimin e mesem te ulet. Lenda: Matematike. (Klasa e nente) [Curriculum for lower secondary school. Subject: Mathematics. (Grade 9)]. Available from http://izha.edu.al/programet/ klasa9/03Matematika\%209\%20final,\%202008.pdf

Institute of Curricula and Training (2008). Programi i lendes se matematikes per klasen e 10-te [Mathematics curriculum for Grade 10]. Available from http://izha.edu.al/ programet/klasa10/berthame/6.1\%20Matematike\%2010.pdf

Julie, C. (2007). The context learners prefer for mathematical literacy and their link to present-day issues in South Africa. In C. Haines, P. Galbraith, W. Blum, \& S Khan (Eds.), Mathematical modelling: Education, engineering and economics ( $\mathrm{pp}$. 195-202). Chichester: Horwood Publishing Limited.

Julie, C. (2009). Appropriate contexts for teacher in-service courses: Perspectives of practicing teachers. South African Journal of Higher Education, 23(1), 113-126.

Julie, C., \& Holtman, L. (2008). The relevance of school mathematics education (ROSME). In L. Holtman, C. Julie, $\varnothing$. Mikalsen, D. Mtetwa, \& M. Ogunniyi (Eds.), Some developments in research in science and mathematics in Sub-Sahara Africa: Access, relevance, learning, curriculum research (pp. 379-405). Somerse West, South Africa: African Minds. Available from http://www.africanminds. co.za/21.htm

Julie, C., Holtman, L., \& Mbekwa, M. (2011). Rasch modelling of Mathematics and Science teachers' preferences of real-life situations to be used in Mathematica Literacy. Pythagoras, 32(1), Art. \#13, 8 pages. http://dx.doi.org/10.4102/ pythagoras.v32i1.13
Julie, C., \& Mbekwa, M. (2005). What would grade 8 to 10 learners prefer as context for mathematical literacy? The case of Masilakele secondary school. Perspectives in Education, 23(3), 31-43.

Kacerja, S. (2009). Contexts Albanian students prefer to use in Mathematics (Pilot study). In M. Tzekaki, D. Kaldrimidou, \& C. Sakonidis (Eds.), Proceedings of the 33rd Conference of the International Group for the Psychology of Mathematics Education, 20-24 July 2009, Vol. 1 (p. 473). Thessaloniki, Greece: PME.

Kacerja, S., Julie, C., \& Hadjerrouit, S. (2010). The contexts Albanian students prefer to use in Mathematics and relationship to contemporary matters in Albania. In V. Mudaly (Ed.), Proceedings of the 18th Annual Meeting of the Southern African Association for Research in Mathematics, Science and Technology Education, 2226 January 2010, Vol. 1 (pp. 319-328). Durban: SAARMSTE.

Kaiser-Messmer, G. (1993). Results of an empirical study into gender differences in attitudes towards mathematics. Educational Studies in Mathematics, 25, 209233. http://dx.doi.org/10.1007\%2FBF01273862

Kvale, S., \& Brinkmann, S. (2009). Qualitative interviews. Learning the craft of qualitative research interviewing. Thousand Oaks, CA: Sage publications.

Lojerat e fatit shtyjnë të miturit drejt krimeve [Gambling pushes minors toward crime] (2009, 30 January). Gazeta Shqip. Available from http://lajme.shqiperia.com/ lajme/artikull/iden/183186/titulli/Lojerat-e-fatit-shtyjne-te-miturit-drejt-krimeve

Meaney, T. (2007). Weighing up the influence of context on judgements of mathematical literacy. International Journal of Science and Mathematics Education, 5(4), 681-704. http://dx.doi.org/10.1007/s10763-007-9093-8

National Mathematics Advisory Panel. (2008). Foundations for success: The final report of the National Mathematics Advisory Panel. Washington, DC: US Department of Education. Available from http://www2.ed.gov/about/bdscomm/list/mathpanel/ report/final-report.pdf

Organisation for Economic Co-operation and Development (OECD) (2006). Assessing scientific, reading and mathematical literacy. A framework for PISA 2006. Paris: OECD. Available from http://www.oecd.org/dataoecd/63/35/37464175.pdf

Pawson, R. (1996). Theorizing the interview. British Journal of Sociology, 47(2), 295314.

Pawson, R., \& Tilley, N. (1997). Realistic evaluation. London: Sage Publications.

Pierce, R., \& Stacey, K. (2006). Enhancing the image of mathematics by association with simple pleasures from real word contexts. ZDM: The International Journal on Mathematics Education, 38(3), 214-225. http://dx.doi.org/10.1007/BF02652806

Pring, R. (2004). Philosophy of educational research (2nd edn.). London: Continuum.

Qualifications and Curriculum Authority. (2007). Mathematics. Programme of study for key stage 3 and attainment target. Available from http://curriculum.qcda.gov. uk/uploads/QCA-07-3336-p_ICT_KS3_tcm8-401.pdf

Sahlberg, P., \& Boce, E. (2008, March). Are we teaching for a knowledge society? Evidence from Albanian upper secondary schools. Paper presented at the Annual Meeting of the American Educational Research Association, New York.

Sultana, R.G. (2006). Facing the hidden drop-out challenge in Albania. Evaluation report of hidden drop-out project. Piloted in basic education in 6 prefectures of Albania. Tirana, Albania: UNICEF.

United Nations Development Programme (UNDP). (2009). Human development report 2010. The real wealth of nations: Pathways to human development. Available from http://hdr.undp.org/en/reports/global/hdr2010/chapters/en/

Van den Heuvel-Panhuizen, M. (2005). The role of contexts in assessment problems in mathematics. For the Learning of Mathematics, 25(2), 2-9. Available from http:// www.jstor.org/stable/40248489

World Bank. (2005). Albania: Poverty and education in Albania - who benefits from public spending? Annex II. To Albania long term development issues and options. Washington, DC: World Bank. 